\title{
Regulation of Tyrosine Hydroxylase Promoter Activity by Chronic Morphine in TH9.0-LacZ Transgenic Mice
}

\author{
Virginia A. Boundy, ${ }^{1}$ Stephen J. Gold, ${ }^{1}$ Chad J. Messer, ${ }^{1}$ Jingshan Chen, ${ }^{1}$ Jin H. Son, ${ }^{2}$ \\ Tong H. Joh, ${ }^{2}$ and Eric J. Nestler ${ }^{1}$ \\ ${ }^{1}$ Laboratory of Molecular Psychiatry, Departments of Psychiatry and Neurobiology, Yale University School of Medicine \\ and Connecticut Mental Health Center, New Haven, Connecticut 06508, and 2Laboratory of Molecular Neurobiology, \\ Cornell University Medical Center, White Plains, New York 10605
}

Levels of tyrosine hydroxylase (TH), the rate-limiting enzyme in catecholamine biosynthesis, are known to be upregulated in specific brain regions by chronic administration of drugs of abuse. Chronic morphine administration increases $\mathrm{TH}$ levels in the locus coeruleus and ventral tegmental area, whereas chronic cocaine administration increases $\mathrm{TH}$ levels in the ventral tegmental area only. While such upregulation of $\mathrm{TH}$ has been related to behavioral effects of the drugs, the mechanism underlying these adaptations has remained controversial. To study the possibility that upregulation of $\mathrm{TH}$ occurs at the transcriptional level, we investigated the effect of chronic morphine or cocaine treatment on the activity of the $\mathrm{TH}$ gene promoter $(9.0 \mathrm{~kb})$, coupled to the LacZ reporter gene, in transgenic mice. These TH9.0-LacZ mice have been shown to exhibit correct tissue-specific expression and regulation of the reporter gene. We show here that chronic (but not acute) exposure of the TH9.0-LacZ mice to morphine increases the expression of $\beta$-galactosidase (which is encoded by the LacZ gene) in the locus coeruleus by twofold compared with shamtreated mice. In contrast, $\beta$-galactosidase expression in the ventral tegmental area was decreased $20-25 \%$ by chronic morphine and unaffected by chronic cocaine administration. Similar results were obtained after analysis of TH mRNA levels in these brain regions by in situ hybridization. These results suggest that chronic morphine upregulates $\mathrm{TH}$ expression via transcriptional mechanisms in the locus coeruleus but by posttranscriptional mechanisms in the ventral tegmental area.

Key words: opiate dependence; cocaine; locus coeruleus; ventral tegmental area; in situ hybridization; transcriptional regulation; catecholamines
Drug addiction is thought to represent a form of neural plasticity (Nestler et al., 1993). According to this view, chronic exposure to a drug of abuse alters the expression of specific proteins in localized regions of the brain, which then lead to the behavioral manifestations of the addicted state. One of the most consistent biochemical changes seen in response to chronic drug exposure is upregulation of tyrosine hydroxylase $(\mathrm{TH})$, the rate-limiting enzyme in the biosynthesis of the catecholamine neurotransmitters norepinephrine and dopamine.

In the locus coeruleus (LC), the major noradrenergic nucleus in brain, chronic morphine administration has been shown to increase levels of TH immunoreactivity and catalytic activity (Guitart et al., 1990; Lane-Ladd et al., 1997). This upregulation would be expected to increase the capacity of these neurons to synthesize norepinephrine, which could contribute to the dramatic increase in norepinephrine release seen in target regions of the LC and to associated behavioral changes during opiate withdrawal (Koob et al., 1992; Grasing et al., 1997).

In the ventral tegmental area (VTA), a major midbrain dopaminergic nucleus, levels of TH expression are upregulated in response to chronic administration of several drugs of abuse,

\footnotetext{
Received May 21, 1998; revised Sept. 1, 1998; accepted Sept. 15, 1998.

This work was supported by grants from the National Institute on Drug Abuse and by the Abraham Ribicoff Research Facilities of the Connecticut Mental Health Center, State of Connecticut Department of Mental Health and Addiction Services. We thank Ms. Rose Terwilliger for excellent technical assistance.

Correspondence should be addressed to Dr. Virginia Boundy, Ergo Science Corporation, 100 First Avenue, 4th floor, Charlestown, MA 02129-2051.

Copyright (C) 1998 Society for Neuroscience $0270-6474 / 98 / 189989-07 \$ 05.00 / 0$
}

including morphine, cocaine, amphetamine, or alcohol (BeitnerJohnson and Nestler, 1991; Hurd et al., 1992; Persico et al., 1993; Sorg et al., 1993; Vrana et al., 1993; Ortiz et al., 1995; Masserano et al., 1996). Such upregulation of TH could contribute to the complex effects that these drugs exert on dopaminergic transmission, which has been implicated in the reinforcing actions of these and most other drugs of abuse (Koob, 1996; Kuhar and Pilotte, 1996; Wise, 1996).

However, the mechanism by which chronic drug exposure upregulates $\mathrm{TH}$ expression in these brain regions has been the subject of some controversy. With respect to the LC, chronic morphine administration has been shown to increase levels of TH mRNA in one study (Guitart et al., 1990); this effect was not seen in another study (Holmes et al., 1995). Similarly, reports of the effect of chronic cocaine or amphetamine administration on $\mathrm{TH}$ mRNA levels in the VTA have been both positive (Hurd et al., 1992; Persico et al., 1993; Vrana et al., 1993) and negative (Sorg et al., 1993), whereas the effect of chronic morphine exposure has not yet been studied. The technical difficulty of reliably detecting changes in mRNA levels in nuclei as small as the LC and VTA may have contributed to these discrepancies.

Therefore, to gain greater insight into the mechanisms underlying drug regulation of $\mathrm{TH}$ in these brain regions, we studied a recently developed transgenic mouse line, in which expression of LacZ (a reporter gene) is under the control of a $9.0 \mathrm{~kb}$ portion of the TH gene promoter (Min et al., 1994). LacZ expression in this mouse shows correct tissue distribution (i.e., it closely follows that of the endogenous TH gene) and can be induced in the LC by 
reserpine administration (Min et al., 1996), which is known to dramatically induce TH mRNA in this brain region (Cubells et al., 1995). We show here that chronic administration of morphine to TH9.0-LacZ mice dramatically increases LacZ expression in the LC, whereas chronic administration of morphine or cocaine failed to produce this effect in the VTA. Studies of TH mRNA levels in the LC and VTA by in situ hybridization are consistent with these latter findings. Together, the results support a scheme whereby upregulation of $\mathrm{TH}$ in the LC occurs at least in part at the transcriptional level, whereas upregulation of TH in the VTA occurs post-transcriptionally.

\section{MATERIALS AND METHODS}

Production and identification of transgenic animals. Male mice from the transgenic line TH9.0-LacZ-5, described previously (Min et al., 1994), were bred and the progeny identified by dot-blot or PCR analysis of tail DNA.

In vivo morphine and cocaine treatments. Chronic morphine treatment involved the subcutaneous implantation of morphine pellets under light halothane anesthesia. For mice, the pellets contained $25 \mathrm{mg}$ of morphine base (National Institute on Drug Abuse) and were implanted on days 1 and 3; for rats (200 gm initial weight; Sprague Dawley, Charles River Laboratories, Wilmington, MA), the pellets contained $75 \mathrm{mg}$ of morphine base and were implanted daily on days $1-5$. Rats and mice were killed on day 6 . These treatments are known to cause profound states of tolerance, dependence, and withdrawal in both species; they also induce TH immunoreactivity in the LC of both species (Guitart and Nestler, 1989; Guitart et al., 1990; Rasmussen et al., 1990; Widnell et al., 1992). Control animals received sham surgeries (which in some cases included implantation with placebo pellets) on the same schedule and under the same anesthesia as treated animals. No differences were observed, in this or in previous studies from this laboratory (Beitner-Johnson and Nestler, 1991), between animals receiving sham surgery with or without placebo pellet implantation. As a result, the two groups were combined and are presented herein as control. Acute morphine treatment involved the subcutaneous injection of morphine sulfate in $0.9 \%$ saline $(10 \mathrm{mg} / \mathrm{kg}$; National Institute on Drug Abuse) with mice used 45 min later, when some acute biochemical changes are maximal. Control mice received saline injections. Chronic cocaine treatment involved intraperitoneal injections of cocaine in $0.9 \%$ saline $(20 \mathrm{mg} / \mathrm{kg}$; National Institute of Drug Abuse) daily for $7 \mathrm{~d}$. Animals were killed on day 8, $18 \mathrm{hr}$ after the final injection. This treatment regimen elicits characteristic biochemical and behavioral changes of cocaine, including induction of TH in the VTA, in rats and mice (Fitzgerald et al., 1996; Hiroi et al., 1997). Control animals received saline injections.

Mouse tissue preparation and $X$-gal histochemistry. Transgenic mice were anesthetized with Nembutol $(0.2 \mathrm{ml} / 100 \mathrm{gm}$; Abbott Labs, North Chicago, IL), perfused transcardially with $0.9 \%$ saline followed by fixative $(0.5 \%$ paraformaldehyde, $2 \%$ glutaraldehyde in $0.1 \mathrm{~m}$ phosphate buffer, $\mathrm{pH}$ 7.4). Brains were removed, blocked, post-fixed in the same fixative solution for $12-18 \mathrm{hr}$, and cryoprotected with $20 \%$ glycerol in 50 mM phosphate buffer, $\mathrm{pH}$ 7.4. Using a sliding microtome, $40-\mu \mathrm{m}$-thick coronal sections were obtained for X-gal histochemistry. Histological procedures have been described in detail previously (Min et al., 1994, 1996). Briefly, to visualize expression of the LacZ reporter gene, sections were incubated with a solution containing $3.1 \mathrm{~mm}$ potassium ferricyanide, $3.1 \mathrm{~mm}$ potassium ferrocyanide, $0.15 \mathrm{M} \mathrm{NaCl}, 1 \mathrm{~mm} \mathrm{MgCl}, 0.01 \%$ sodium deoxycholate, $0.02 \%$ Nonidet P- 40 , and $0.2 \mathrm{mg} / \mathrm{ml} \mathrm{X-gal} \mathrm{in} 10 \mathrm{~mm}$ phosphate buffer, $\mathrm{pH}$ 7.4. The activity of $\beta$-galactosidase on the X-gal substrate results in an insoluble blue dye. For quantification, adjacent sections were incubated for $15 \mathrm{~min}, 1 \mathrm{hr}, 4 \mathrm{hr}$, or $16 \mathrm{hr}$ as described (Min et al., 1996). Sections were rinsed in $10 \mathrm{~mm}$ phosphate buffer, $\mathrm{pH} 7.4$, mounted, counter-stained with Neutral Red, dehydrated, and coverslipped in Permount (Fisher Scientific, Fair Lawn, NJ).

Quantitative analysis of $\beta$-galactosidase expression. Computer-assisted digital analysis and densitometry were performed on slide-mounted brain sections. Several sections in the middle of the anteroposterior extent of the region of interest (LC or VTA) were analyzed as identified using standard landmarks (Franklin and Paxinos, 1997). Great care was taken to match the control and treated sections by location in this anteroposterior axis. Optical density (OD) measurements were obtained from LC and VTA in control and treated mice using NIH Image software in a manner similar to that described previously (Min et al., 1996). According to NIH Image software, "relative OD" reflects the OD measured in a sample relative to an internal reference value. At a constant level of illumination, the absorbance of the light by the blue dye, generated in the reaction of $\beta$-gal on X-gal, corresponds directly to an increase in OD.

Western blot analysis. Brains were removed rapidly from decapitated mice, and the LC and VTA were excised using a 15 gauge syringe needle as reported previously for the rat (Guitart et al., 1990; Beitner-Johnson and Nestler, 1991). Samples were homogenized in 2\% SDS. Aliquots of LC (containing $20 \mu \mathrm{g}$ of protein) and VTA (containing $10 \mu \mathrm{g}$ of protein) were loaded on $7.5 \%$ SDS-polyacrylamide gels, electrophoresed, and transferred to nitrocellulose (Schleicher \& Schuell, Keene, NH). Nitrocellulose blots were immunolabeled for TH exactly as described (LaneLadd et al., 1997) using a rabbit polyclonal antiserum against TH (diluted 1:10000, kindly provided by Dr. John Haycock, Louisiana State University) and enhanced chemiluminescence (Amersham, Arlington Heights, IL). Blots were exposed to film and analyzed using densitometry (NIH Image). Equal loading and transfer of proteins were confirmed by amido black staining.

In situ hybridization. Coronal brain sections (14- $\mu \mathrm{m}$-thick) were cut on a cryostat (Reichart Jung) at $-20^{\circ} \mathrm{C}$ and thaw-mounted onto glass slides (Probe-on Plus; Fisher Scientific). Correct anatomical location of sections was determined by standard landmarks (Sklair-Tavron et al., 1996; Gold et al., 1997) and confirmed by Nissl staining of selected sections. An in situ hybridization protocol, modified from Brené et al. (1998), was used. The probe was a 48-mer oligonucleotide derived from the $\mathrm{TH}$ mRNA sequence (5'-CGT GGG CCA GGG TGT GCA CCT CAT CCT GGA CCC CCT CCA AGG AGC GCT-3'). This sequence is not homologous to the coding sequence of other aromatic acid hydroxylases such as dopamine $\beta$-hydroxylase or tryptophan hydroxylase. The $\mathrm{TH}$ oligonucleotide was $3^{\prime}$-end-labeled with ${ }^{35}$ S-dATP (NEN DuPont, Boston, MA) using terminal deoxynucleotide transferase (Life Technologies, Grand Island, NY) to a specific activity of $1 \times 10^{9} \mathrm{cpm} / \mu \mathrm{g}$, and separated from unlabeled probe on a Nensorb-20 column (NEN DuPont). The hybridization solution contained $50 \%$ formamide, $4 \times$ SSC $(1 \times$ SSC: $0.15 \mathrm{~m} \mathrm{NaCl}$ and $0.015 \mathrm{~m}$ sodium citrate, $\mathrm{pH} 7.0), 1 \times$ Denhardt's solution, $1 \%$ Sarcosyl, $0.02 \mathrm{M}$ sodium phosphate, $\mathrm{pH} 7.0,10 \%$ dextran sulfate, $0.06 \mathrm{M} \mathrm{DTT}$, and $0.1 \mathrm{mg} / \mathrm{ml}$ sheared salmon sperm DNA. TH probe $\left(5 \times 10^{6} \mathrm{cpm} / \mathrm{ml}\right)$ was added to the hybridization solution, and each section was incubated in $0.1 \mathrm{ml}$ overnight in a humidified chamber at $42^{\circ} \mathrm{C}$. After hybridization, sections were rinsed four times in $0.5 \times \mathrm{SSC}$ for $20 \mathrm{~min}$ at $60^{\circ} \mathrm{C}$, rinsed for $10 \mathrm{sec}$ in sterile water, dehydrated in alcohol, and air-dried. Slides were then exposed to x-ray film for 2-4 weeks. OD values were quantified on a Macintosh-based NIH Image analysis program using a ${ }^{14} \mathrm{C}$ step standard (Amersham).

\section{RESULTS}

\section{Regulation of TH promoter activity in the LC by chronic morphine}

The ability of chronic morphine to regulate the activity of the TH promoter in the LC in vivo was examined in TH9.0-LacZ transgenic mice. Changes in the activity of the promoter in these mice were represented by alterations in the expression of the LacZ gene product, $\beta$-galactosidase. X-gal histochemistry on slidemounted brain slices from mice treated with chronic morphine revealed a marked upregulation of transgene expression to $\sim 200 \%$ of that seen in sham-treated mice (Fig. 1). Qualitatively, basal expression presented as lighter overall staining with discrete punctate areas of higher staining (Fig. $1 A, C, E, G$ ). In chronic morphine-treated mice, however, the $\mathrm{X}$-gal reaction produced darker staining with increased cellular filling by the blue dye (Fig. $1 B, D, F, H)$. A time course analysis using digitized LC images was performed to compare quantitatively the relative levels of X-gal staining after reaction times of $15 \mathrm{~min}$ (Fig. $1 A, B$ ), $1 \mathrm{hr}$ (Fig. $1 C, D), 4 \mathrm{hr}$ (Fig. $1 E, F)$, and $16 \mathrm{hr}$ (Fig. $1 G, H)$. Such a time course is critical for accurate measurement of differences in $\beta$-galactosidase expression (Min et al., 1996). In mice treated chronically with morphine, elevated X-gal staining was evident as little as $15 \mathrm{~min}$ after initiation of the reaction (Fig. $1 B$ ). A similar degree of upregulation of $\beta$-galactosidase expression by chronic morphine was evident qualitatively (Fig. 1) and quantitatively 

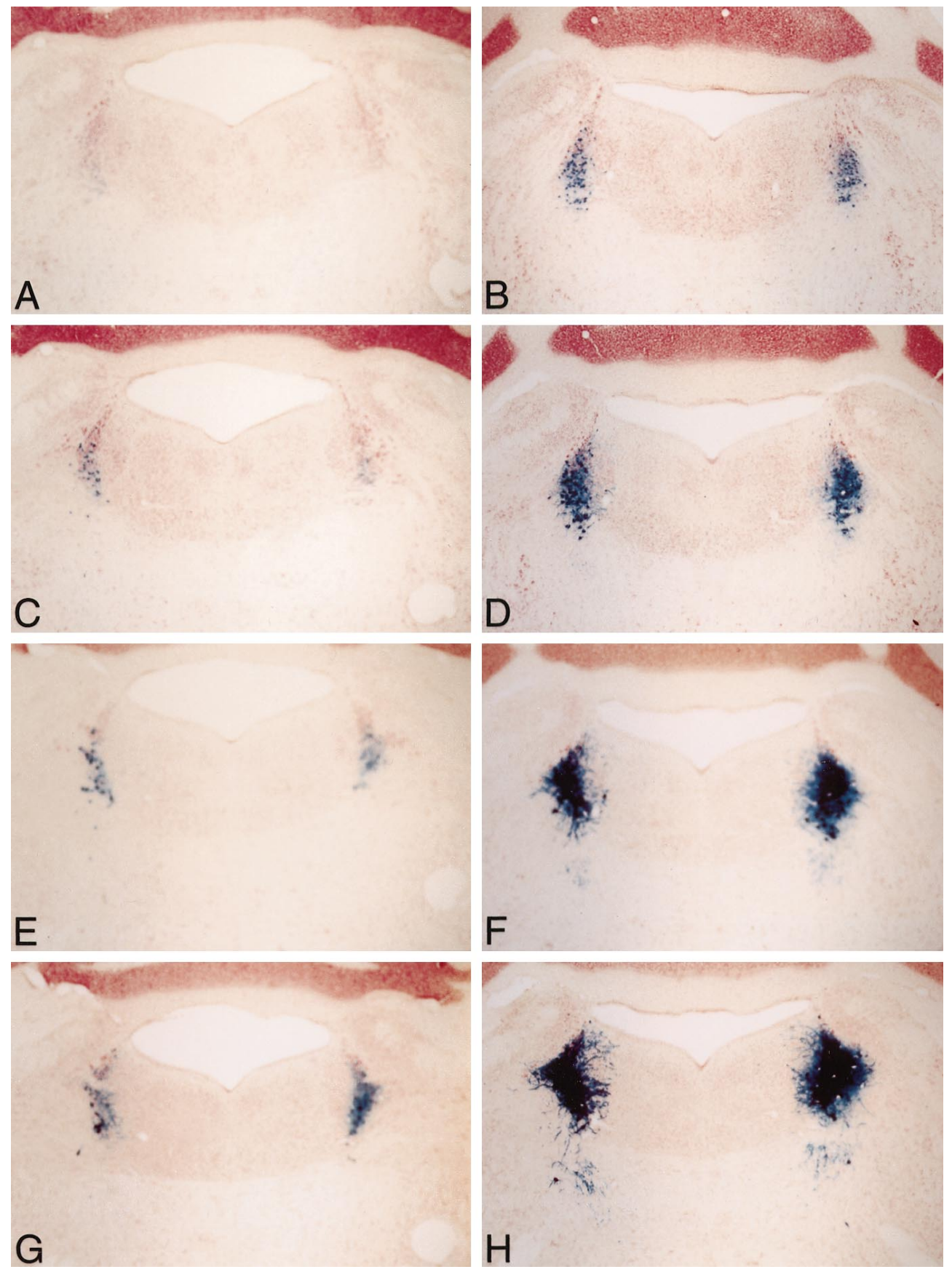

Figure 1. Expression of $\beta$-galactosidase in the LC of TH9.0-LacZ mice after chronic treatment with morphine. Low-power photomicrographs of representative brain slices through the LC of sham-treated mice $(A, C, E, G)$ or chronic morphine-treated mice $(B, D, F$, $H)$ are shown. Expression of $\beta$-galactosidase was visualized with X-gal histochemistry, performed as described in Materials and Methods, with reaction times of $15 \min (A, B), 1 \mathrm{hr}(C, D), 4 \mathrm{hr}$ $(E, F)$, or $16 \mathrm{hr}(G, H)$.
(Fig. 2, Table 1) at every reaction time. In contrast, acute exposure to morphine failed to alter levels of $\beta$-galactosidase expression in the LC (Table 1).

\section{Regulation of TH promoter activity in the VTA by chronic morphine}

The effect of chronic morphine administration on $\mathrm{TH}$ promoter activity in the VTA was also examined in the same TH9.0-LacZ transgenic mice. X-gal histochemistry revealed decreased staining in the VTA of morphine-treated mice (Fig. $3 B$ ) compared with sham-treated mice (Fig. $3 A$ ). Quantitatively, this corresponded to a significant $20-25 \%$ reduction in $\beta$-galactosidase expression, which was seen throughout the time course of X-gal reactions (Fig. 3C, Table 1). In contrast, acute exposure to morphine failed to alter levels of $\beta$-galactosidase expression in the VTA (Table 1).
In previous studies, it was found that the ability of chronic morphine to induce $\mathrm{TH}$ immunoreactivity in the rat VTA was dependent on the strain of rat used: most strains showed this effect, whereas some did not (Guitart et al., 1992). As a result, it was important to confirm that the small reduction in $\mathrm{TH}$ promoter activity seen in the VTA of TH9.0-LacZ mice, in contrast to the increase in TH immunoreactivity seen in the rat VTA, did not reflect a rat-mouse species difference or the genetic background of the TH9.0-LacZ mice. Indeed, as shown in Figure 4, there was a more than twofold induction of $\mathrm{TH}$ immunoreactivity in the VTA of TH9.0-LacZ mice in response to chronic morphine administration, which is similar to the increase seen in several rat strains. There was also a significant increase in $\mathrm{TH}$ immunoreactivity in the LC of these animals (data not shown). 


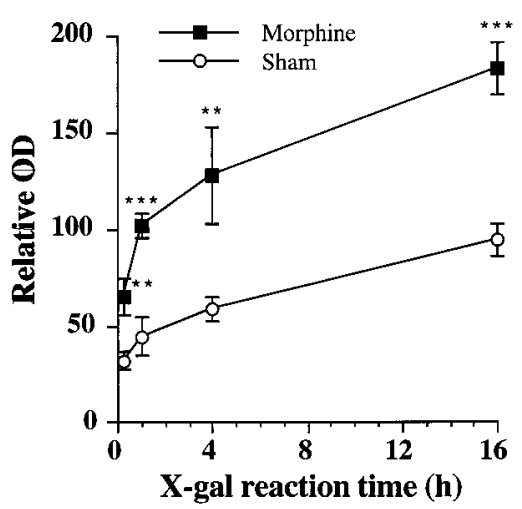

Figure 2. Quantitative analysis of $\beta$-galactosidase expression in the LC of TH9.0-LacZ mice after chronic treatment with morphine. Mice received sham treatment $(n=4)$ or chronic morphine treatment $(n=4)$, and $\beta$-galactosidase expression was visualized, as described in Materials and Methods. Digital analysis and densitometry were performed on the LC of slide-mounted brain sections (see Materials and Methods). Data shown are the means $\pm \mathrm{SD} .{ }^{*} p=0.01 ; * * * p=0.001$, compared with sham-treated mice by $t$ test.

\section{Regulation of TH promoter activity in the LC and VTA by chronic cocaine}

We next examined the effect of chronic cocaine administration on $\beta$-galactosidase expression in TH9.0-LacZ transgenic mice. In contrast to chronic morphine treatment, chronic exposure to cocaine failed to alter levels of $\beta$-galactosidase expression in the LC or VTA compared with saline-treated animals (Table 1).

\section{Regulation of TH mRNA levels by chronic morphine and chronic cocaine}

To provide further information on the mechanisms by which chronic drug exposure alters TH expression in the LC and VTA, levels of TH mRNA were studied in this brain region of Sprague Dawley rats by in situ hybridization. This analysis revealed the expected pattern of labeling of TH-positive neurons in these two brain regions. As shown in Figure 5, right, chronic administration of morphine increased levels of TH mRNA in the LC compared with sham-treated controls $(146 \pm 10 \%$ mean \pm SEM of shamtreated animals; $n=6 ; p<0.05$ by $t$ test). In contrast, there was no significant effect of chronic morphine on TH mRNA levels in the VTA ( $124 \pm 12 \%$ of sham-treated animals; $n=9 ; p>0.1$ by $t$ test) (Fig. 5, left). Chronic administration of cocaine also failed to alter levels of TH mRNA in this brain region $(111 \pm 3 \%$ of sham-treated animals; $n=5 ; p>0.1$ ). This lack of effect of morphine and cocaine exposure on TH mRNA levels in the VTA was demonstrated throughout the rostrocaudal extent of the nucleus.

\section{DISCUSSION}

Results of the present study provide important new insight into the mechanisms by which chronic exposure to a drug of abuse increases levels of TH immunoreactivity in the LC and VTA. In the LC, chronic administration of morphine dramatically increases TH promoter activity, an effect not seen with acute morphine exposure. In contrast, chronic administration of morphine or cocaine failed to increase $\mathrm{TH}$ promoter activity in the VTA; in fact, there was a small but significant decrease observed in the case of morphine. Consistent with these findings, we found

Table 1. $\beta$-galactosidase expression in the LC and VTA of TH9.0-LacZ mice after morphine or cocaine treatments

\begin{tabular}{llccc} 
& LC & & VTA \\
\cline { 2 - 4 } Treatment & Sham & Treated & Sham & $100 \pm 15$ \\
Acute morphine (5) & $100 \pm 7$ & $97 \pm 9$ & $100 \pm 6$ & \\
Chronic morphine (4) & $100 \pm 9$ & $194 \pm 14^{* *}$ & $10 \pm \pm 11$ \\
Chronic cocaine (6) & $100 \pm 15$ & $97 \pm 16$ & $100 \pm 9$ & $103 \pm 10$ \\
\hline
\end{tabular}

Mice received sham, morphine, or cocaine treatments, and $\beta$-gal expression was visualized and quantified, as described in Materials and Methods. Data shown are the means \pm $\mathrm{SD}$ expressed as percentage of $\beta$-gal expression in control mice after X-gal histochemistry (16 hr reaction time). Number of animals in each group is noted in parentheses. ${ }^{*} p=0.05 ; * *=0.001$, compared with sham treatment by $t$ test.
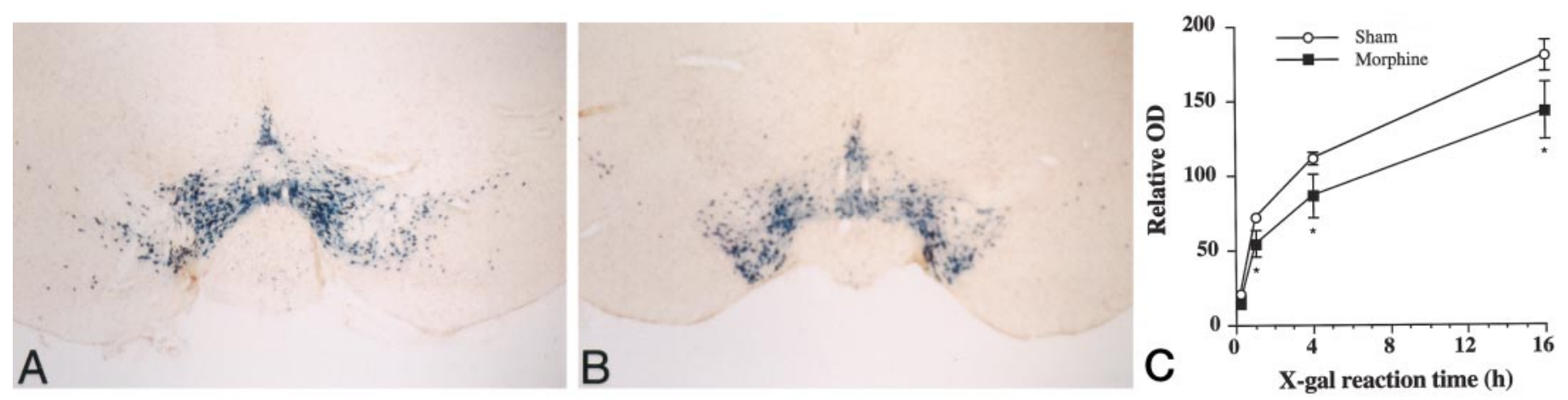

Figure 3. Expression of $\beta$-galactosidase in the VTA of TH9.0-LacZ mice after chronic treatment with morphine. Mice received sham treatment $(n=$ 4 ) or chronic morphine treatment $(n=4)$, and $\beta$-galactosidase expression was visualized with X-gal histochemistry, performed as described in Materials and Methods. Low-power photomicrographs of representative brain slices through the VTA of sham-treated mice $(A)$ or morphine-treated mice $(B)$ are shown (for $16 \mathrm{hr}$ X-gal reaction time). $C$, Quantitative analysis of $\beta$-galactosidase expression was performed on the VTA region of slide-mounted brain sections for $15 \mathrm{~min}, 1 \mathrm{hr}, 4 \mathrm{hr}$, or $16 \mathrm{hr}$ X-gal reaction times (see Materials and Methods). Data shown are the means $\pm \mathrm{SD}$. * $p=0.05$, compared with sham mice by $t$ test. 

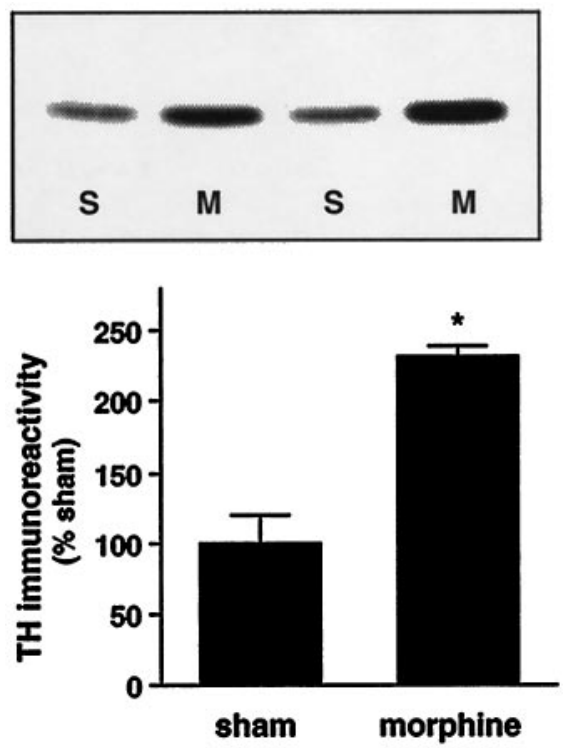

Figure 4. Regulation of TH immunoreactivity in the mouse VTA after chronic treatment with morphine. TH9.0-LacZ mice received chronic sham $(S)$ or morphine $(M)$ treatment, and levels of TH immunoreactivity were determined by Western blotting, as described in Materials and Methods. Representative autoradiograms are shown. Data are expressed as mean percent of sham $\pm \operatorname{SEM}(n=6) ;{ }^{*} p<0.001$ by $t$ test.
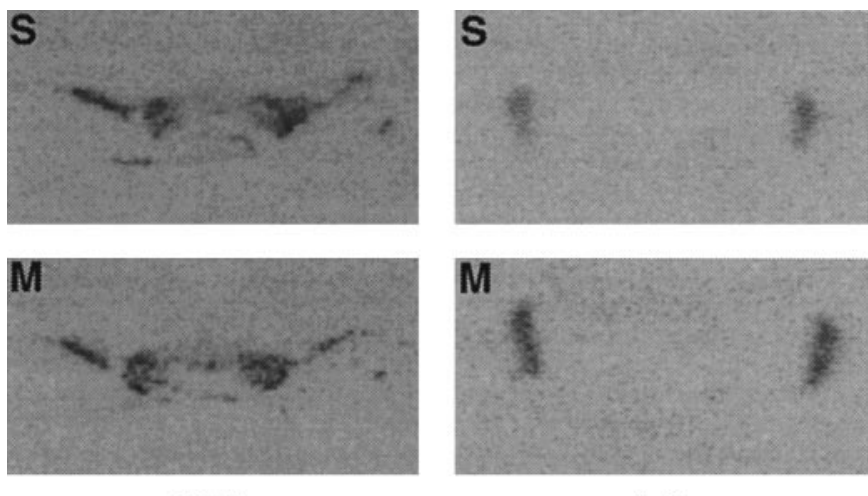

VTA

Figure 5. Expression of TH mRNA in the rat VTA after chronic treatment with morphine. Rats received chronic sham $(S)$ or morphine $(M)$ treatment, and levels of TH mRNA were determined by in situ hybridization, as described in Materials and Methods. Low-power autoradiographs of representative brain slices through the VTA (left) and LC (right) are shown. The figure is representative of results obtained from six to nine animals in each treatment group.

increased levels of TH mRNA in the LC after chronic morphine administration, but no significant changes in the VTA after chronic exposure to either morphine or cocaine. Together, these results support the view that upregulation of TH immunoreactivity in the LC in response to chronic morphine administration is achieved at least in part via transcriptional mechanisms, whereas such upregulation in the VTA in response to chronic morphine or cocaine is achieved via post-transcriptional mechanisms.

Our findings in the LC confirm the results of an earlier study in which chronic morphine administration was shown to increase levels of TH mRNA in rat LC as determined by northern blotting (Guitart et al., 1990). The reason why a more recent report (Holmes et al., 1995) failed to detect such an increase by in situ hybridization remains unknown, but could be related to the technical difficulties in quantifying mRNA levels in a brain micronucleus as small as the LC. Another possible explanation for the contrasting results are the different morphine treatment conditions under which TH mRNA was measured in the two studies. In the present study, as well as in Guitart et al. (1990), we used pellets that provide continuous exposure to morphine, and the mRNA was measured $18 \mathrm{hr}$ after implantation of the final pellet; it is known that no withdrawal is encountered at this time point because of the sustained release of morphine from the pellets (Rasmussen et al., 1990). In contrast, in the previous report (Holmes et al., 1995), morphine was administered via daily intermittent injections, and the mRNA was measured $27 \mathrm{hr}$ after the final injection, at which point some spontaneous withdrawal might be expected. A still further explanation is that the $\beta$-galactosidase assay of TH promoter activity in the TH9.0-LacZ mice is a far more powerful and sensitive method for studying $\mathrm{TH}$ expression in brain micronuclei. Indeed, our results with the TH9.0-LacZ mice demonstrate that morphine upregulation of $\mathrm{TH}$ expression in the $\mathrm{LC}$ is clear and robust.

The possibility, based on the present studies of the TH9.0-LacZ mice, that upregulation of TH in LC is transcriptionally mediated is supported by a recent study with antisense oligonucleotides to the transcription factor cAMP response element-binding protein (CREB) (Lane-Ladd et al., 1997). In this investigation, infusion of CREB antisense oligonucleotides directly into the LC was shown to decrease basal levels of $\mathrm{TH}$ as well as completely prevent the ability of chronic morphine to upregulate this protein. These findings are consistent with the overwhelming evidence from in vitro studies that the TH gene is highly regulated and that a single CRE (the DNA response element on which CREB acts) present in the $5^{\prime}$-promoter region of the $\mathrm{TH}$ gene plays a critical role in basal TH expression and the dramatic induction of expression that can be elicited by several perturbations, including activation of the cAMP pathway (Hiremagalur et al., 1993; Kim et al., 1993a,b, 1994; Lazaroff et al., 1995). Because chronic morphine treatment is known to upregulate the cAMP pathway in LC neurons (Nestler, 1996; Nestler and Aghajanian, 1997), a likely scheme for induction of $\mathrm{TH}$ in this brain region is that upregulation of the cAMP pathway leads to increased CREB function, which in turn activates $\mathrm{TH}$ gene transcription.

In contrast, the mechanisms by which chronic morphine or cocaine administration upregulates $\mathrm{TH}$ immunoreactivity in the VTA would appear to be less straightforward. In this region, there is no induction of $\mathrm{TH}$ promoter activity; with chronic morphine there was even a small decrease, despite a robust increase in $\mathrm{TH}$ immunoreactivity detected by western blotting. There also was no significant change in TH mRNA levels in the VTA after chronic administration of morphine or cocaine. Although our results do not rule out the possibility that an increase in TH mRNA might occur earlier in the course of drug exposure, there is no evidence to support this possibility. Previous studies of cocaine regulation of TH mRNA levels in the VTA have been mixed (Sorg et al., 1993; Vrana et al., 1993), although both of these studies reported an increase in $\mathrm{TH}$ immunoreactivity. Regardless of these discrepancies, however, our findings with the TH9.0-LacZ mice demonstrate clearly that post-transcriptional mechanisms are likely responsible for the increased levels of $\mathrm{TH}$ immunoreactivity seen after chronic drug exposure. There are several precedents from cultured cells and from adrenal medullary chromaffin cells that TH levels can be influenced via such mechanisms (for review, see Kumer and Vrana, 1996). For exam- 
ple, there is evidence that the stability of TH mRNA, the translational efficiency of $\mathrm{TH}$ mRNA, and the stability of the $\mathrm{TH}$ protein are each subject to dynamic regulation. These various mechanisms now warrant direct examination for involvement in chronic morphine and cocaine action in the VTA.

That the morphine- and cocaine-induced upregulation of TH immunoreactivity in the VTA involves complex, posttranscriptional mechanisms may not be surprising given previously documented drug effects in this brain region. Thus, chronic morphine or cocaine exposure has been shown to decrease levels of neurofilament proteins in the VTA (Beitner-Johnson et al., 1992). In the case of chronic morphine, this is associated, as would be expected, with impaired axoplasmic transport from the VTA to one of its major targets, the nucleus accumbens (BeitnerJohnson and Nestler, 1993). It is also associated with morphological changes in VTA dopamine neurons: the neurons are smaller in size, have smaller caliber processes, and appear more spherical in shape after chronic morphine exposure (Sklair-Tavron et al., 1996). One possibility, then, is that upregulation of TH immunoreactivity occurs, in part, as a result of the accumulation of $\mathrm{TH}$ molecules within these structurally altered neuronal cell bodies. This could then trigger a small compensatory decrease in $\mathrm{TH}$ gene transcription, as observed in the present study. Further examination of this and alternative possibilities is now needed to better understand this phenomenon.

In summary, results of the present study provide new information on the mechanisms that underlie drug-induced upregulation of $\mathrm{TH}$ in specific brain regions. The results show that upregulation of the same protein, in response to the same drug treatment, in two types of neuron (e.g., LC noradrenergic vs VTA dopaminergic neurons) can occur via very different mechanisms. The results also illustrate the unique potential of using transgenic mice as tools to investigate the molecular basis of drug action. Finally, although the results support the likely importance of transcriptional regulation in mediating some of the actions of drugs of abuse on the brain, they clearly implicate nontranscriptional mechanisms as well. In general, less is known about such nontranscriptional mechanisms, which are particularly difficult to study in the brain in vivo. Nevertheless, better understanding of these mechanisms would appear to be necessary to delineate the precise molecular events by which chronic administration of a drug of abuse leads to an array of adaptations that are ultimately responsible for a state of addiction.

\section{REFERENCES}

Beitner-Johnson D, Nestler EJ (1991) Morphine and cocaine exert common chronic actions on tyrosine hydroxylase in dopaminergic brain reward regions. J Neurochem 57:344-347.

Beitner-Johnson D, Nestler EJ (1993) Chronic morphine impairs axoplasmic transport in the mesolimbic dopamine system of the rat brain. NeuroReport 5:57-60.

Beitner-Johnson D, Guitart X, Nestler EJ (1992) Neurofilaments and the mesolimbic dopamine system: Common regulation by chronic morphine and chronic cocaine in the rat ventral tegmental area. J Neurosci 12:2165-2176.

Brené S, Messer CJ, Nestler E (1998) Expression of mRNAs encoding ionotropic glutamate receptors in rat brain: regulation by haloperidol. Neuroscience 84:813-823.

Cubells JF, Kim KS, Baker H, Volpe BT, Chung Y, Houpt TA, Wessel TC, Joh TH (1995) Differential in vivo regulation of mRNA encoding the norepinephrine transporter and tyrosine hydroxylase in rat adrenal medulla and locus ceruleus. J Neurochem 65:502-509.

Fitzgerald LW, Ortiz J, Hamedani AG, Nestler EJ (1996) Regulation of glutamate receptor subunit expression by drugs of abuse and stress: common adaptations among cross-sensitizing agents. J Neurosci $16: 274-282$.
Franklin KBJ, Paxinos G (1997) The mouse brain in stereotaxic coordinates. New York: Academic.

Gold SJ, Ni YG, Dohlman H, Nestler EJ (1997) Regulators of G protein signaling: Region-specific expression of nine subtypes in rat brain. J Neurosci 17:8024-8037.

Grasing K, Bills D, Ghosh S, Schlussman SD, Patel AH, Woodward JJ (1997) Opiate modulation of striatal dopamine and hippocampal norepinephrine release following morphine withdrawal. Neurochem Res 22:239-248.

Guitart X, Nestler EJ (1989) Identification of morphine- and cyclic AMP-regulated phosphoproteins (MARPPs) in the locus coeruleus and other regions of rat brain: regulation by acute and chronic morphine. J Neurosci 9:4371-4387.

Guitart X, Hayward M, Nisenbaum LK, Beitner-Johnson D, Haycock JW, Nestler EJ (1990) Identification of MARPP-58, a morphine- and cyclic AMP-regulated phosphoprotein of $58 \mathrm{kDa}$, as tyrosine hydroxylase: evidence for regulation of its expression by chronic morphine in the rat locus coeruleus. J Neurosci 10:2649-2659.

Guitart X, Beitner-Johnson X, Marby D, Kosten TA, Nestler EJ (1992) Fischer and Lewis rats strains differ in basal levels of neurofilament proteins and their regulation by chronic morphine in the mesolimbic dopamine system. Synapse 12:242-253.

Hiremagalur B, Nankova B, Nitahara J, Zeman R, Sabban EL (1993) Nicotine increases expression of tyrosine hydroxylase gene. Involvement of protein kinase A-mediated pathway. J Biol Chem 268:23704-23711.

Hiroi N, Brown J, Haile C, Ye H, Greenberg ME, Nestler EJ (1997) FosB mutant mice: loss of chronic cocaine induction of Fos-related proteins and heightened sensitivity to cocaine's psychomotor and rewarding effects. Proc Natl Acad Sci USA 94:10397-10402.

Holmes PV, de Bartolomeis A, Koprivica V, Crawley JN (1995) Lack of effect of chronic morphine treatment and naloxone-precipitated withdrawal on tyrosine hydroxylase, galanin, and neuropeptide Y mRNA levels in the rat locus coeruleus. Synapse 19:197-205.

Hurd YL, Lindefors N, Brodin E, Brené S, Persson H, Ungerstedt U, Hokfelt T (1992) Amphetamine regulation of mesolimbic dopamine/ cholecystokinin neurotransmission. Brain Res 578:317-326.

Kim KS, Lee MK, Carroll J, Joh TH (1993a) Both the basal and inducible transcription of the tyrosine hydroxylase gene are dependent upon a cAMP response element. J Biol Chem 268:15689-15695.

Kim KS, Park DH, Wessel TC, Song B, Wagner JA, Joh TH (1993b) A dual role for the cAMP-dependent protein kinase in tyrosine hydroxylase gene expression. Proc Natl Acad Sci USA 90:3471-3475.

Kim KS, Tinti C, Song B, Cubells JF, Joh TH (1994) Cyclic AMPdependent protein kinase regulates basal and cyclic AMP-stimulated but not phorbol ester-stimulated transcription of the tyrosine hydroxylase gene. J Neurochem 63:834-842.

Koob GF (1996) Drug addiction: the yin and yang of hedonic homeostasis. Neuron 16:893-896.

Koob GF, Maldonado R, Stinus L (1992) Neural substrates of opiate withdrawal. Trends Neurosci 15:186-191.

Kuhar MJ, Pilotte NS (1996) Neurochemical changes in cocaine withdrawal. Trends Pharmacol Sci 17:260-264.

Kumer SC, Vrana KE (1996) Intricate regulation of tyrosine hydroxylase activity and gene expression. J Neurochem 67:443-462.

Lane-Ladd SB, Pineda J, Boundy VA, Pfeuffer T, Krupinski J, Aghajanian GK, Nestler EJ (1997) CREB in the locus coeruleus: biochemical, physiological, and behavioral evidence for a role in opiate dependence. J Neurosci 17:7890-7901.

Lazaroff M, Patankar S, Yoon SO, Chikaraishi DM (1995) The cyclic AMP response element directs tyrosine hydroxylase expression in catecholaminergic central and peripheral nervous system cell lines from transgenic mice. J Biol Chem 270:21579-21589.

Masserano JM, Baker I, Natsukari N, Wyatt RJ (1996) Chronic cocaine administration increases tyrosine hydroxylase activity in the ventral tegmental area through glutaminergic- and dopaminergic $\mathrm{D}_{2}$-receptor mechanisms. Neurosci Lett 217:73-76.

Min N, Joh TH, Kim KS, Peng C, Son JH (1994) 5' upstream DNA sequence of the rat tyrosine hydroxylase gene directs high-level and tissue-specific expression to catecholaminergic neurons in the central nervous system of transgenic mice. Mol Brain Res 27:281-289.

Min N, Joh TH, Corp ES, Baker H, Cubells JF, Son JH (1996) A transgenic mouse model to study transsynaptic regulation of tyrosine hydroxylase gene expression. J Neurochem 67:11-18. 
Nestler EJ (1996) Under siege: the brain on opiates. Neuron 16:897-900.

Nestler EJ, Aghajanian GK (1997) Molecular and cellular basis of addiction. Science 278:58-63.

Nestler EJ, Hope BT, Widnell KL (1993) Drug addiction: a model for the molecular basis of neural plasticity. Neuron 11:995-1006.

Ortiz J, Fitzgerald LW, Charlton M, Lane S, Trevisan L, Guitart X, Shoemaker W, Duman RS, Nestler EJ (1995) Biochemical actions of chronic ethanol exposure in the mesolimbic dopamine system. Synapse 21:289-298.

Persico AN, Schindler CW, Brannock MT, Gonzalez AM, Surratt CK, Uhl GR (1993) Dopaminergic gene expression during amphetamine withdrawal. NeuroReport 4:41-44.

Rasmussen K, Beitner DB, Krystal JH, Aghajanian GK, Nestler EJ (1990) Opiate withdrawal and the rat locus coeruleus: behavioral, electrophysiological, and biochemical correlates. J Neurosci 10: 2308-2317.
Sklair-Tavron L, Shi WX, Lane SB, Harris HW, Bunney BS, Nestler EJ (1996) Chronic morphine induces visible changes in the morphology of mesolimbic dopamine neurons. Proc Natl Acad Sci USA 93: 11202-11207.

Sorg BA, Chen SY, Kalivas PW (1993) Time course of tyrosine hydroxylase expression after behavioral sensitization to cocaine. J Pharmacol Exp Ther 266:424-430.

Vrana SL, Vrana KE, Koves TR, Smith JE, Dworkin SI (1993) Chronic cocaine administration increases CNS tyrosine hydroxylase enzyme activity and mRNA levels and tryptophan hydroxylase enzyme activity levels. J Neurochem 61:2262-2268.

Widnell KL, Bergson C, Clark JA, Nestler EJ (1992) Molecular mechanisms of chronic morphine upregulation of the cAMP in the locus coeruleus. Soc Neurosci Abstr 18:815.

Wise RA (1996) Neurobiology of addiction. Curr Opin Neurobiol 6:243-251. 